\title{
Direct-Liquid-Evaporation Chemical Vapor Deposition of Nanocrystalline Cobalt Metal for Nanoscale Copper Interconnect Encapsulation
}

\section{Citation}

Feng, Jun, Xian Gong, Xiabing Lou, and Roy G. Gordon. 2017. “Direct-Liquid-Evaporation Chemical Vapor Deposition of Nanocrystalline Cobalt Metal for Nanoscale Copper Interconnect Encapsulation." ACS Applied Materials \& Interfaces 9 (12) (March 16): 10914-10920. doi:10.1021/ acsami.7b01327.

\section{Published Version}

10.1021/acsami.7b01327

\section{Permanent link}

http://nrs.harvard.edu/urn-3:HUL.InstRepos:34557644

\section{Terms of Use}

This article was downloaded from Harvard University's DASH repository, and is made available under the terms and conditions applicable to Open Access Policy Articles, as set forth at http:// nrs.harvard.edu/urn-3:HUL.InstRepos:dash.current.terms-of-use\#OAP

\section{Share Your Story}

The Harvard community has made this article openly available.

Please share how this access benefits you. Submit a story.

Accessibility 


\section{Direct-liquid-evaporation Chemical Vapor}

\section{Deposition of Nanocrystalline Cobalt Metal for}

\section{Nanoscale Copper Interconnect Encapsulation}

Jun Feng ${ }^{\dagger}$, Xian Gong ${ }^{\ddagger}$, Xiabing Lou ${ }^{\dagger}$, and Roy G. Gordon ${ }^{*,+, \neq}$

${ }^{\dagger}$ Department of Chemistry and Chemical Biology, Harvard University, Cambridge, MA 02138, USA

‡ John A. Paulson School of Engineering and Applied Sciences, Harvard University, Cambridge, MA 02138, USA

KEYWORDS: cobalt, copper encapsulation, metal interconnect, DLE-CVD, nanocrystalline

ABSTRACT: In advanced microelectronics, precise design of liner and capping layers becomes critical, especially when it comes to the fabrication of $\mathrm{Cu}$ interconnects with dimensions lower than its mean free path. Herein, we demonstrate that direct-liquid-evaporation chemical vapor deposition (DLE-CVD) of Co is a promising method to make liner and capping layers for nanoscale $\mathrm{Cu}$ interconnects. DLE-CVD makes pure, smooth, nanocrystalline and highly conformal Co films with highly controllable growth characteristics. This process allows full Co 
encapsulation of nanoscale $\mathrm{Cu}$ interconnects, thus stabilizing $\mathrm{Cu}$ against diffusion and electromigration. Electrical measurements and high-resolution elemental imaging studies show that the DLE-CVD Co encapsulation layer can improve the reliability and thermal stability of $\mathrm{Cu}$ interconnects. Also, with the high conductivity of Co, the DLE-CVD Co encapsulation layer can potentially further decrease the power consumption of nanoscale $\mathrm{Cu}$ interconnects, paving the way for $\mathrm{Cu}$ interconnects with higher efficiency in future high-end microelectronics.

\section{Introduction}

Continued progress in the downsizing of microelectronic devices has brought great challenges in many fields, especially interfacial engineering and interconnect fabrication at nanometer scales. ${ }^{1-}$ ${ }^{2}$ As a critical part of transmitting signals among microelectronic units, metal interconnect architectures have been calling for exponentially increased integration density and complexity in the past decades. ${ }^{3}$ One of the greatest obstacles limiting the industry from further scaling down copper $(\mathrm{Cu})$ interconnects, which is the most widely used interconnect material, is the electromigration (EM) and diffusion of $\mathrm{Cu}^{4-6}$ Various barrier, liner and capping layers for $\mathrm{Cu}$ interconnects have been reported in the effort to stabilize $\mathrm{Cu}$ atoms by suppressing their diffusion and migration, including $\mathrm{SiN}_{\mathrm{x}}$, $\mathrm{SiCN}$ and transition metal nitrides. ${ }^{7-9}$ However, when it comes to a $22 \mathrm{~nm}$ technology node and below, dimensions of interconnects are already less than the mean free path (MFP) of $\mathrm{Cu}(\sim 40 \mathrm{~nm})$, while $\mathrm{Cu}$ metal conductivity decreases exponentially as it shrinks in size below MFP due to surface and grain boundry scattering. ${ }^{10-12}$ As a result, by adding several nanometers of a low conductivity tantalum nitride barrier layer $\left(\sim 10^{6} \mathrm{~S} / \mathrm{m}\right)$ onto $\mathrm{Cu}\left(5.96 \times 10^{7} \mathrm{~S} / \mathrm{m}\right)$, the effective width of a Cu wire would be decreased by $10-20 \%$, thus 
drastically decreasing the overall conductivity of the nanoscale interconnects. ${ }^{13-14}$ Therefore, a high-conductivity metallic material with $\mathrm{Cu}$ stabilization functionalities is needed for furtherdown-sized microelectronic interconnects.

Cobalt (Co) and Co alloys are known as effective capping layers that are capable of suppressing surface electromigration of $\mathrm{Cu}$ at macroscopic scales ${ }^{15-16}$ Furthermore, since Co has a high bulk metallic conductivity of $1.60 \times 10^{7} \mathrm{~S} / \mathrm{m}$ and an estimated MFP of only $\sim 16 \mathrm{~nm}$ at room temperature, it is emerging as a promising candidate for advanced $\mathrm{Cu}$ liner/capping layers. ${ }^{17-18}$ Traditionally, Co metal was deposited by PVD methods that do not have the capability of coating inside high-aspect-ratio structures. ${ }^{19}$ Thus, metal-organic chemical vapor deposition (MOCVD) with cobalt carbonyl precursors [e.g., $\mathrm{Co}_{2}(\mathrm{CO})_{8}$ ] was introduced for better conformality. ${ }^{20}$ However, cobalt carbonyl precursors have poor thermal stability and narrow useful deposition temperature windows, and usually lead to a rough film with surface roughness rms higher than $2.2 \mathrm{~nm} .{ }^{21}$ Recently, our group reported novel direct-liquid-evaporation chemical vapor deposition (DLE-CVD) methods for metal and metal nitride thin films, which provided the feasibility to create higher-quality Co films over a wide range of deposition temperatures and low chance of pre-deposition decomposition of precursors. ${ }^{22-23}$

When a precursor is vaporized from a conventional bubbler, the actual rate of vapor delivery is subject to many variables, including drifts in the bubbler temperature, the amount of precursor remaining in the bubbler, and thermal decomposition during long times at high temperatures. In contrast, precursors in DLE-CVD systems are stored at room temperature, so that thermallyinduced decomposition is negligible. The precursor is heated only very briefly after it flows into a heated evaporation region, so that its decomposition is negligible during its short heating time. The precursor delivery rate is stably controlled and measured by a liquid flow-controller 
immediately before it flows into the evaporation region. ${ }^{24}$ In making nanoscale metal interconnects, it is critical to have precise control over all deposition processes in order to guarantee reliability and reproducibility. For liners and capping layers of copper interconnects, it is particularly important to design deposition conditions that create continuous and pinhole-free films with nano-sized crystallinity for blocking the diffusion of copper. ${ }^{25}$

In this report, we demonstrate with nanoscale elemental imaging and electrical measurements that precisely controlled DLE-CVD of Co metal films is a promising liner and capping layer for nanoscale $\mathrm{Cu}$ interconnects. Narrow $\mathrm{Cu}$ wires encapsulated all-around by DLE-CVD Co were fabricated as illustrated in Figure 1. In-depth study of temperature-dependent deposition characteristics and atom probe tomography (APT) analysis are conducted to understand better the kinetics of DLE-CVD Co growth and its atomic-scale morphology. APT imaging studies showed that our DLE-CVD Co forms a smooth nanocrystalline film with a grain size of $\sim 10 \mathrm{~nm}$ and surface roughness rms of $\sim 0.9 \mathrm{~nm}$. Electrical measurements on microcapacitors show that $\mathrm{Cu}$ is effectively blocked from diffusing into the $\mathrm{SiO}_{2}$ dielectric layer by our DLE-CVD Co. This work provides direct evidence that encapsulating nanoscale $\mathrm{Cu}$ interconnects with nanocrystalline DLE-CVD Co can substantially improve its stability and suppress diffusion of $\mathrm{Cu}$ atoms, paving the way for improved $\mathrm{Cu}$ interconnects in advanced microelectronics.

\section{Experimental Section}

Co DLE-CVD details: The precursor used in this work is a cobalt amidinate, bis $\left(N, N^{\prime}-\right.$ diisopropylacetamidinato) cobalt(II) (Figure S1), which has been reported previously. ${ }^{23,} 26$ Tetradecane (Millipore Sigma Chemical Co.) was distilled from sodium to remove moisture before use. All chemical operations were conducted in a glove box with a nitrogen atmosphere. 
Cobalt precursor solution was prepared by dissolving $5 \mathrm{~g}$ of Co precursor in $50 \mathrm{ml}$ of tetradecane. The CVD of Co is conducted with a home-made direct-liquid-evaporation (DLE) system (Figure S2). During the deposition process, a precisely controlled precursor solution flow (12 wt\% in tetradecane) is injected into and vaporized in a heated vaporization loop, in which a constant 100 cubic centimeters per minute (sccm) of $\mathrm{N}_{2}$ is flowing as a carrier gas. Then the precursor vapor is mixed with 100 sccm purified ammonia $\left(\mathrm{NH}_{3}\right)$ and 100 sccm hydrogen $\left(\mathrm{H}_{2}\right)$ as co-reactant gases, and delivered into a preheated deposition chamber (16 inch long and 1.25 inch diameter) with an 11 inch $\times 1.25$ inch semi-cylindrical sample holder inside. The total pressure in the reactor chamber is also regulated and maintained at 10 Torr, in which the partial pressures of $\mathrm{NH}_{3}, \mathrm{H}_{2}$ and $\mathrm{N}_{2}$ all equal 3.23 Torr. The Co precursor partial pressure varied from 0.02 Torr to 0.08 Torr in this work. Based on the calculation of reaction zone volume and flow rates, it takes roughly 13 s for a precursor molecule to be delivered across the reaction zone on statistical average.

APT sample preparation and analysis parameters: The Cameca LEAP 4000X HR system was used for APT analysis. $25 \mathrm{~nm}$ of Co films by different deposition conditions were deposited onto pre-sharpened silicon microtips (PSMs). The final needle-shaped specimens have a tip radius between $50 \mathrm{~nm}$ and $70 \mathrm{~nm}$, and with shank angles around $10^{\circ}$. The analyses were carried out at $40 \mathrm{~K}$ under a vacuum pressure lower than $5 \times 10^{-11}$ Torr. A $532 \mathrm{~nm}$ laser with $50 \mathrm{pJ}$ pulse energy was used to assist ion evaporation at a pulse frequency of $100 \mathrm{kHz}$. Data reconstruction was performed with IVAS software (Cameca, Gennevilliers, France), extracting three-dimensional quantitative compositional and structural information. ${ }^{27}$

Fabrication of trench test structure: A flat silicon chip was first coated with $2 \mu \mathrm{m}$ of positive photoresist as a soft mask, and patterned with $500 \mu \mathrm{m}$ wide $0.5 \mathrm{~cm}$ long exposed lines by photolithography. A $500 \mu$ m wide, $2 \mu \mathrm{m}$ deep shallow trench was created by a Bosch-type deep 
silicon reactive ion etching (DRIE) process with $\mathrm{SF}_{6}$ and $\mathrm{C}_{4} \mathrm{~F}_{6}$ gases, and thoroughly cleaned afterwards. Finally, the chip was physically capped with another flat silicon chip to cover part of the $0.5 \mathrm{~cm}$ length, leaving one end exposed as the opening of the parallel deep trench.

Micro-capacitor fabrications and measurements: In order to evaluate the copper barrier performance of DLE-CVD Co, a p-type silicon chip with $50 \mathrm{~nm}$ thermal oxide layers was coated with $10 \mathrm{~nm}$ DLE-CVD Co at $200{ }^{\circ} \mathrm{C}$ followed by $50 \mathrm{~nm}$ PVD Cu, then annealed at $600{ }^{\circ} \mathrm{C}$ for $1 \mathrm{~h}$ under 1 Torr of flowing $\mathrm{N}_{2}$. After annealing, the $\mathrm{Cu}$ and Co films were removed by wet etching in order to fabricate micro-capacitors. $50 \mu \mathrm{m}$ x $50 \mu \mathrm{m}$ square-shaped Au electrodes were then fabricated by standard photolithography, metallization and lift-off process. For comparison, nonannealed samples were also fabricated into micro-capacitors. The micro-capacitors were measured by a probe station with a Keysight E4980A precision LCR meter. Capacitance versus voltage $(\mathrm{C}-\mathrm{V})$ characteristics were measured at $2 \mathrm{MHz}$ with a sweep rate of $0.2 \mathrm{~V} / \mathrm{s}$. All measurements started at positive $5 \mathrm{~V}$ and scanned from positive bias toward negative bias.

Other characterization details: The cross-sectional morphology of the films was visualized with a Zeiss Ultra Plus field-emission scanning electron microscope (FE-SEM), from which the thickness of each film was measured. A Zeiss Ultra55 with EDAX detector was used to acquire EDAX mapping images. The depth-profile elemental analysis was carried out by Thermo Scientific K-Alfa X-ray photoelectron spectroscopy (XPS). A JEOL 2100 transmission electron microscope was used to study microscopic crystallography for which the samples were prepared onto a TEM grid with an ultrathin silicon nitride membrane. X-ray diffraction patterns were acquired by a Bruker D2 Phaser. Surface morphology of the films was analyzed by atomic force microscopy (AFM) (Asylum Model MFP-3D AFM system). Step coverage evaluation of DLECVD Co was conducted on a planar trench structure as shown in Figure S3 and Figure S4. The 
nanoscale $\mathrm{Cu}$ lines for $\mathrm{Cu}$ encapsulation were patterned by an Elionix F-125 ultra-high precision electron beam lithography system, and metallized by electron beam evaporation of $\mathrm{Cu}$.

\section{Results and Discussion}

In order to understand the deposition process of DLE-CVD cobalt metal, we conducted a series of temperature-dependent studies. In all depositions, co-reactant gas flows are set to be $100 \mathrm{sccm} \mathrm{NH}_{3}$ and $100 \mathrm{sccm} \mathrm{H}_{2}$, and the precursor solution concentration is fixed at $12 \mathrm{wt} \%$, which were evaluated to be the best conditions for high conformality and smoothness according to our previous report. ${ }^{23}$ Figure 2a plots the growth rates of DLE-CVD Co versus precursor solution flow rates at different temperatures. The results show that our deposition process is highly controllable by precisely setting precursor flow rates and temperatures. A lower temperature with a lower flow rate is suitable for nano-scale applications such as local interconnect and nanoscale capping layer, while a higher temperature with higher flow rate is favorable for larger-scale coatings such as intermediate and global interconnects in 3D

microelectronics. ${ }^{7}$ By plotting the natural logarithm of growth rate versus the reciprocal of temperature (Figure $\mathbf{2 b}$ ), we calculated the activation energies of Co deposition processes with different precursor flow rates based on the Arrhenius' equation. The activation energy is estimated to be $63.1 \pm 1.2 \mathrm{~kJ} / \mathrm{mol}$ on silicon substrates, which is in accordance with a previous report on thermal oxide substrates. ${ }^{28-29}$

To demonstrate the step coverage of our DLE-CVD Co films, we developed a parallel trench structure with an ultrahigh aspect ratio as a test platform. The fabrication of this trench structure is described in the experiments section, as well as schematically illustrated in Figure S3 in the supporting information. Co films were then deposited on the test structure by DLE-CVD at 
various temperatures at a constant precursor flow rate of $5 \mathrm{~g} / \mathrm{h}$. Cross-section SEM images were acquired to measure film thickness at different depths (as shown in Figure S4 in the supporting information), showing that our $200{ }^{\circ} \mathrm{C}$ film has over $95 \%$ step coverage at a 10:1 aspect ratio, and maintains $50 \%$ step coverage even at a $70: 1$ aspect ratio. $230{ }^{\circ} \mathrm{C}$ and $260{ }^{\circ} \mathrm{C}$ films both have over $90 \%$ step coverage at a 10:1 aspect ratio, and maintain $50 \%$ step coverage at 60:1 and 35:1 aspect ratios, respectively.

In addition to high deposition rate and high conformality, low impurity level, e.g., low carbon level, is also required for intermediate and global level interconnects because carbon content can decrease the conductivity of metal interconnects, thus increasing the energy consumption of overall device. ${ }^{30-31}$ X-ray photoelectron spectra (XPS) of DLE-CVD Co samples deposited at different temperatures are provided in Figure 2d. All spectra are taken after $100 \mathrm{~s}$ of $100 \mathrm{eV} \mathrm{Ar}^{+}$ sputtering to remove surface contamination. Substantial amounts of carbon ( $>5$ at\%) are only observed in the samples deposited at above $290{ }^{\circ} \mathrm{C}$. Samples deposited at temperatures up to 230 ${ }^{\circ} \mathrm{C}$ show less than about 1 at $\%$ of carbon contamination. To estimate the impact of carbon content on DLE-CVD Co, we measured the conductivity of Co films with different C contents, which is discussed in the supporting information Table S3. The results show that the resistivity substantially increased when the $\mathrm{C}$ content raise-rose above 5-2 at\%, indicating that the DLECVD Co films deposited at lower than $230{ }^{\circ} \mathrm{C}$ ( $<1$ at\% carbon shown by XPS) will be more promising to achieve better performance as interconnect materials. To further characterize these high-purity films with lower than 1 at\% contaminants, a more sensitive method (APT) is needed to detect and quantify the impurities.

APT is an advanced characterization technique with ultra-high atomic resolution from-for both compositional and morphological-morphologypoints of view. In-During an APT analysis-process, 
individual atoms are electrically evaporated one by one from the surface of a needle-shaped specimen, and analyzed by a 2D mass spectrometer to obtain their chemical and positional information at the same time. ${ }^{32-34}$ APT can detect lower concentrations of atoms than XPS, and is more suitable for the study of our high-purity Co films.

Since DLE-CVD Co samples deposited at $200{ }^{\circ} \mathrm{C}$ and $230{ }^{\circ} \mathrm{C}$ had trace amounts of impurities below the XPS detection limits, we conducted APT analysis on these two samples. As is shown in Figure 3 (a-b), we started the sample preparation by coating DLE-CVD Co films with precisely controlled thickness on silicon microtips pre-sharpened to less than a $10 \mathrm{~nm}$ tip radius and $10^{\circ}$ shank angle. Highly smooth and conformal Co films are observed on the microtips, as is demonstrated in Figure $\mathbf{3 b}$. Laser-assisted APT analysis is then performed on the coated microtips at $40 \mathrm{~K}$. Figure 3c is the 3D atomic reconstruction of the $200{ }^{\circ} \mathrm{C}$ DLE-CVD Co film, in which the surface blue-colored dots are cobalt, green dots are oxygen and grey dots are silicon. No obvious clustering or accumulation of impurities is observed, and most oxygen atoms only exist on the silicon tip surface, which is due to the UV-Ozone cleaning before deposition in order to completely remove organic residues left from the lithography process. In Table $\mathbf{1}$, compositional data are collected from only the film part, excluding the atoms from the silicon tip and its surface. The sample deposited at $200{ }^{\circ} \mathrm{C}$ shows less than 0.8 at $\%$ of each contaminant (C, $\mathrm{N}$ and $\mathrm{O}$ ), and the sample deposited at $230{ }^{\circ} \mathrm{C}$ contains less than 1.8 at $\%$ of these impurities. In APT reconstruction data, mild surface oxidations were observed, which we believe is due to air exposure after taking samples out of deposition chamber for characterizations. This issue can be readily solved by installing tandem deposition setups and finish multiple metallization processes without an air break. With DLE-CVD design, tandem depositions are highly feasible because 
DLE-CVD can deliver multiple precursors solutions from different external precursor containers, and do depositions consecutively, which is another advantage of DLE process.

For $\mathrm{Cu}$ liner/capping layer applications, it is important to develop nanocrystalline Co films for smooth surface coverage of $\mathrm{Cu}$ wires. APT results demonstrate the ultra-high purity and uniformity of our $200{ }^{\circ} \mathrm{C}$ DLE-CVD Co film, but do not provide information about microscopic surface morphology and crystallography. To obtain these characteristics, we performed transmission electron microscopy (TEM) and atomic force microscopy (AFM) imaging on the $200{ }^{\circ} \mathrm{C}$ sample. TEM image shown in Figure 4a presents that the film is a nanocrystalline material with a grain size of around $10 \mathrm{~nm}$. High-resolution imaging of lattice alignments at the grain boundary is included as the inset of Figure 4a. More high-resolution TEM images are also provided in the supporting information Figure S5. Tapping-mode AFM surface scan (Figure 4b) shows a rms surface roughness of $\sim 0.9 \mathrm{~nm}$, indicating that our DLE-CVD process produces highly smooth Co metal film.

X-ray diffraction (XRD) patterns of samples deposited at different temperatures (Figure 4c) reveal that with lower deposition temperatures, the DLE-CVD Co tend to form smaller-sized nanocrystals. Figure 4d presents the electron diffraction (ED) pattern of the $200{ }^{\circ} \mathrm{C}$ DLE-CVD Co sample, in which five major rings are observed. Based on the calculations in Table S1, ring 2 and ring 3 belong to hcp-Co (JCPDS 71-4239), ring 4 and ring 5 belong to fcc-Co (JCPDS 150806), and both phases contribute to the appearance of ring 1 . Those results reveal that our DLECVD Co film is a mixed phase of fcc-Co and hcp Co, which is in accordance with our previous report. ${ }^{23}$ It is our hypothesis that the competing growth between hcp and fcc induced lattice frustration and suppressed the growth of larger crystals, producing nanocrystalline films, which are favorable for $\mathrm{Cu}$ liner/capping applications. ${ }^{35-36}$ 
Based on the Co-Cu phase diagram, $\mathrm{Co}$ and $\mathrm{Cu}$ do not diffuse into each other at temperatures below $700 \mathrm{~K}$, and only partially intermix at temperatures up to $1000 \mathrm{~K}$ from the thermodynamic point of view. ${ }^{37}$ With high conformality, uniformity and smoothness, our nanocrystalline Co films have appropriate properties to be used as an effective copper barrier and capping layer for $\mathrm{Cu}$ interconnects in microelectronics. ${ }^{18,38}$ In order to evaluate the copper barrier performance of our DLE-CVD Co, capacitance-voltage (C-V) characteristics of $\mathrm{Cu} / \mathrm{Co} / \mathrm{SiO}_{2} / \mathrm{Si}$ and $\mathrm{Cu} / \mathrm{SiO}_{2} / \mathrm{Si}$ systems were studied both before and after annealing at $600{ }^{\circ} \mathrm{C}$. Fabrication details of the microcapacitors are described in the experimental section.

Figure 5a presents the $\mathrm{C}-\mathrm{V}$ curve of the $\mathrm{Cu} / \mathrm{SiO}_{2} / \mathrm{Si}$ system, which shows a roughly $2 \mathrm{~V}$ shift toward the negative region after annealing. This phenomenon indicates that $\mathrm{Cu}$ ions diffused into the $\mathrm{SiO}_{2}$ layer and formed positive charges. ${ }^{9}$ However, as shown in Figure $5 \mathbf{b}$, the $\mathrm{Cu} / \mathrm{Co} / \mathrm{SiO}_{2} / \mathrm{Si}$ system presented no observable shift of $\mathrm{C}-\mathrm{V}$ curve, indicating that $\mathrm{Cu}$ is effectively prevented from diffusing into $\mathrm{SiO}_{2}$ by DLE-CVD Co at up to $600{ }^{\circ} \mathrm{C}$. Since Co has much higher conductivity $\left(1.60 \times 10^{7} \mathrm{~S} / \mathrm{m}\right)$ than most metal nitrides, e.g., TaN $\left(0.76 \times 10^{6} \mathrm{~S} / \mathrm{m}\right)$, the application of a Co liner may decrease the thickness of the barrier required for blocking $\mathrm{Cu}$ diffusion, while maintaining a low overall conductivity as close to pure $\mathrm{Cu}\left(5.96 \times 10^{7} \mathrm{~S} / \mathrm{m}\right)$ as possible. ${ }^{8,39-40}$ In this sense, the application of Co can potentially decrease energy consumption during electron transport in $\mathrm{Cu}$ interconnects. ${ }^{15}$ Moreover, the strong adhesion at the $\mathrm{Co} / \mathrm{Cu}$ interface can also substantially suppress surface electromigrations in $\mathrm{Cu}$ interconnects, thus increasing the lifetime of microelectronics devices. ${ }^{41}$

Taking advantage of the $\mathrm{Cu}$ barrier performance, smooth nanocrystallinity and $\mathrm{Cu}$ surface adhesion of DLE-CVD Co, here we demonstrate that a nanocrystalline DLE-CVD Co film is an effective liner/capping material to three-dimensionally encapsulate $\mathrm{Cu}$ interconnects, thus 
enhancing their thermal stability and also suppressing potential electromigration. As a testing platform, nanoscale $\mathrm{Cu}$ wires were encapsulated all-around by DLE-CVD Co on thermal oxide substrates. In detail, a $10 \mathrm{~nm}$ thick Co film is first deposited onto a thermal oxide substrate, then $500 \mathrm{~nm}$ wide $\mathrm{Cu}$ lines with a thickness of $60 \mathrm{~nm}$ were deposited onto the Co surface by standard e-beam lithography, metallization and lift-off processes. Afterwards, a final Co encapsulation layer was deposited onto the $\mathrm{Cu}$ surface by DLE-CVD. Meanwhile, as a control sample, bare $\mathrm{Cu}$ wires with no Co encapsulation layer were also deposited onto a thermal oxide substrate by the same method.

Figure 6 (a-b) shows cross-section EDAX elemental mapping and SEM image of a Coencapsulated $\mathrm{Cu}$ wire, demonstrating that the $\mathrm{Co}$ film is uniformly coated all around the $\mathrm{Cu}$ wire. After annealing at $600{ }^{\circ} \mathrm{C}$ for 2 hours, the EDAX elemental mapping images in Figure 6 (c-d) show that the $\mathrm{Cu}$ distribution is mostly maintained for the $\mathrm{Cu}$ wire sample encapsulated by DLECVD Co. However, as a control experiment, Figure 6 (e-f) indicate that a substantial amount of $\mathrm{Cu}$ diffused into $\mathrm{SiO}_{2}$ when $\mathrm{Co}$ encapsultion is not applied around a $\mathrm{Cu}$ wire, since many more EDAX $\mathrm{Cu}$ counts were detected within the $\mathrm{SiO}_{2}$ layer after annealing. This demonstration provides direct evidence that DLE-CVD Co nanocrystalline films are suitable as liner/capping layers that can substantially increase the reliability and lifetime of nanoscale $\mathrm{Cu}$ interconnects.

\section{Conclusions}

In this work, we demonstrated that DLE-CVD Co with highly controllable growth characteristics is a promising liner/capping layer for nanoscale $\mathrm{Cu}$ interconnects. Microscopic and crystallographic studies show that our DLE-CVD Co is composed of highly smooth nanocrystallines with a grain size of $\sim 10 \mathrm{~nm}$ and surface roughness rms of $\sim 0.9 \mathrm{~nm}$. Less than 
0.8 at $\%$ of impurities was observed in APT analysis results for films deposited at $200{ }^{\circ} \mathrm{C}$. Based on nanoscale analysis of samples with and without Co encapsulation, it is proved that the diffusion of $\mathrm{Cu}$ is effectively blocked by DLE-CVD Co. Finally, with a nanoscale $\mathrm{Cu}$ line encapsulated all-around by Co as a proof-of-concept model, we demonstrate that our DLE-CVD Co encapsulation layer is able to substantially improve the thermal stability of nanoscale $\mathrm{Cu}$ interconnects. Also, taking advatage of the high conductivity and lower carrier MFP of Co, DLECVD Co encapsulation layers can potentially further decrease the power consumption of $\mathrm{Cu}$ interconnects with dimensions smaller than the MFP of $\mathrm{Cu}$. This approach could allow the fabrication of $\mathrm{Cu}$ interconnects with higher efficiency in future microelectronic devices.

Table 1. Compositional data acquired from atom probe tomography

\begin{tabular}{|c|c|c|c|c|}
\hline$\underline{\text { at } \%}$ & $\underline{\underline{\text { Co }}}$ & $\underline{\underline{C}}$ & $\underline{\underline{\mathbf{N}}}$ & $\underline{\underline{\mathbf{O}}}$ \\
\hline $200^{\circ} \mathrm{C}$ & $\underline{\underline{98.00} \pm 0.20}$ & $\underline{\underline{0.76 \pm 0.38}}$ & $\underline{\underline{0.53} \pm 0.28}$ & $\underline{\underline{0.71} \pm 0.25}$ \\
\hline $230^{\circ} \mathrm{C}$ & $\underline{96.80 \pm 0.30}$ & $\underline{1.80 \pm 0.35}$ & $\underline{0.33 \pm 0.18}$ & $\underline{1.07 \pm 0.30}$ \\
\hline
\end{tabular}


(a)
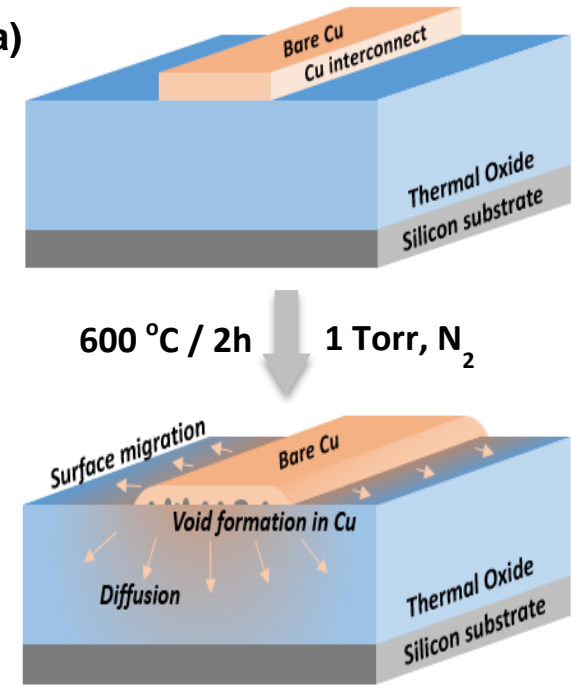

(b)
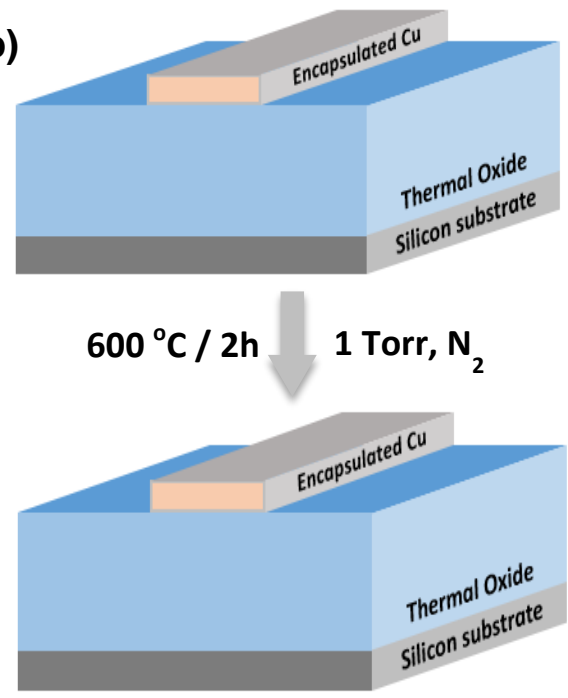

Figure 1. Schematic illustration of preventing the diffusion and deterioration of nanoscale $\mathrm{Cu}$ interconnects by DLE-CVD Co encapsulation. (a) Bare Cu interconnect; (b) Cu interconnect with DLE-CVD Co encapsulation. 

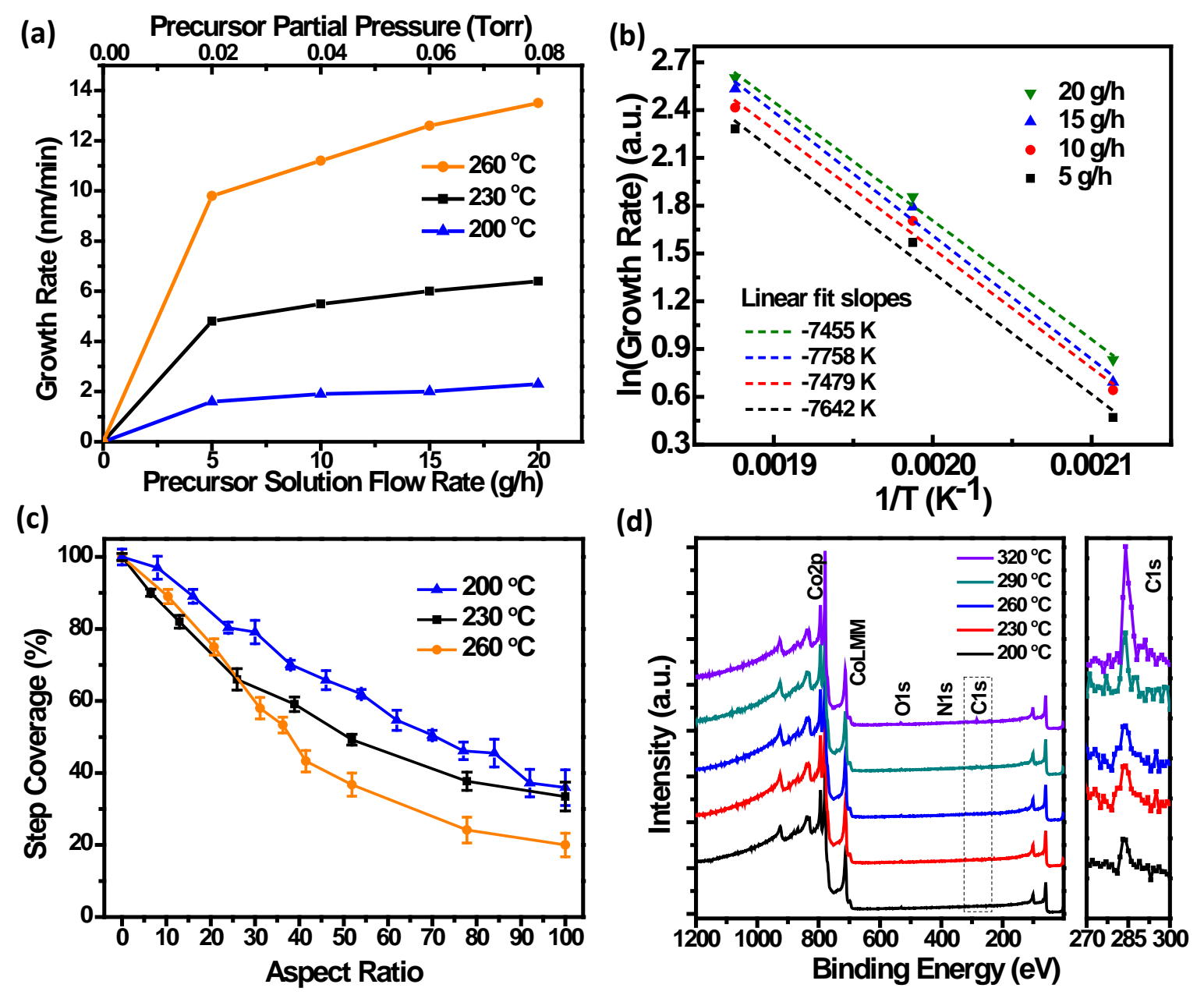

Figure 2. (a) Precursor flow-dependent growth rate plot at different deposition temperatures; Total pressure is 10 Torr in all experiments; (b) Arrhenius plots and linear fits at different precursor flow rates; (c) Step coverage along a horizontal trench test structure (Measurement method is illustrated in Figure S4 in the supporting information); (d) XPS survey scans of DLECVD Co samples deposited at different temperatures; the boxed region is the C1s peak, which is magnified in the graph on the right side. 


\section{Table-1. Gompositional data aquined fromatem probe tomography}

\begin{tabular}{|c|c|c|c|c|}
\hline$=a t \%$ & Ee & $\epsilon$ & $\mathbb{N}$ & $\theta$ \\
\hline $200^{\circ} \mathrm{G}$ & $98.00 \pm 0.20$ & $0.76 \pm 0.38$ & $0.53 \pm 0.28$ & $0.71 \pm 0.25$ \\
\hline $23 \theta^{\theta} \mathrm{G}$ & $96.80 \pm 0.30$ & $1.80 \pm 0.35$ & $0.33 \pm 0.18$ & $1.07 \pm 0.30$ \\
\hline
\end{tabular}
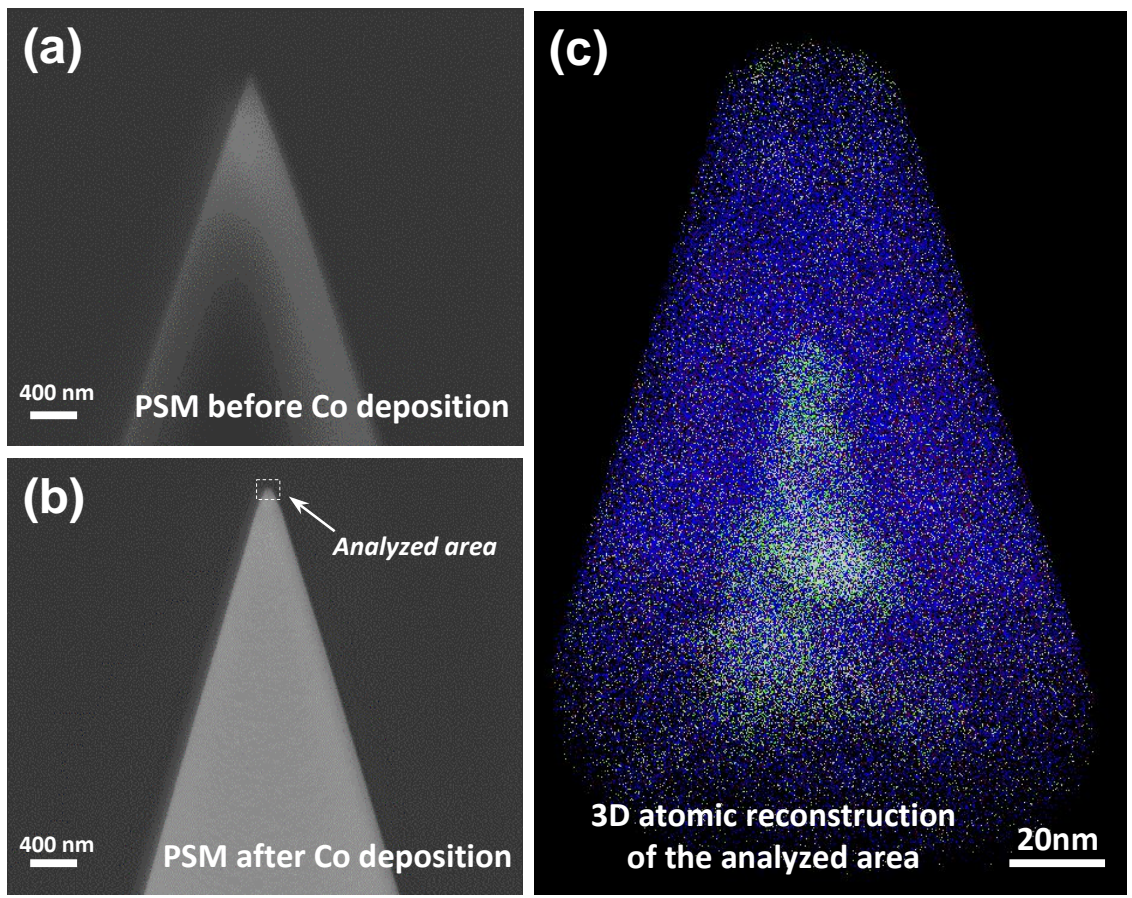

Figure 3. (a) SEM image of PSM before Co deposition; Viewing angle is $30^{\circ}$ from the cone axis; (b) SEM image of PSM after Co deposition; Viewing angle is $30^{\circ}$ from the cone axis; (c) 3D atomic reconstruction of the $200{ }^{\circ} \mathrm{C}$ DLE-CVD specimen, in which blue dots are Co $(0.5 \%$ of all Co atoms displayed), grey dots are Si (50\% displayed), green dots are O (100\% displayed), orange dots are C (100\% displayed), and red dots are N (100\% displayed). 

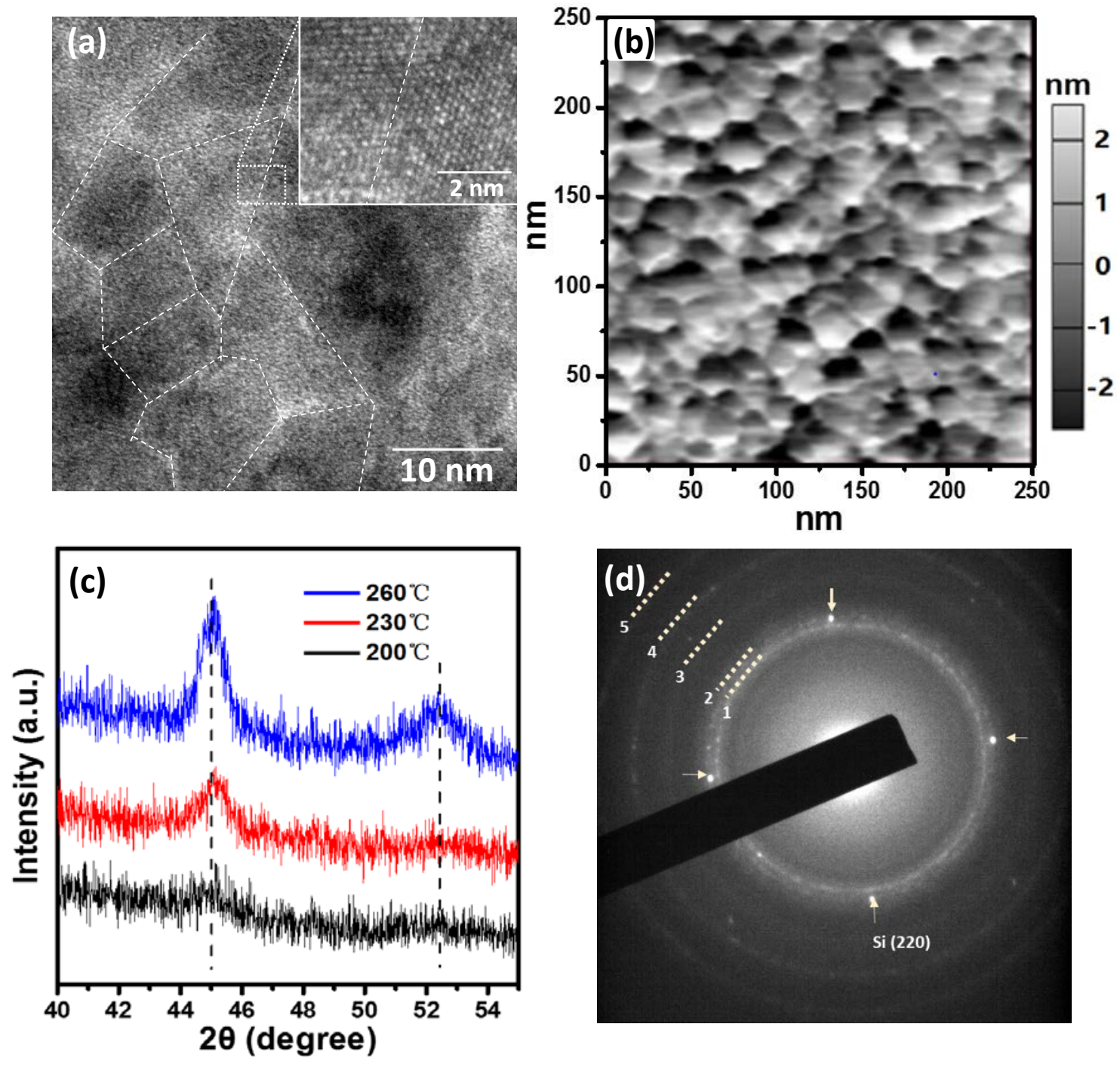

Figure 4. (a) TEM image showing the grain distribution of DLE-CVD Co deposited at $200{ }^{\circ} \mathrm{C}$;

(b) Tapping-mode AFM image of DLE-CVD Co deposited at $200{ }^{\circ} \mathrm{C}$; (c) XRD pattern of DLECVD Co deposited at different temperatures, showing peak broadening at lower temperatures due to the formation of nanocrystallines; (d) ED pattern of DLE-CVD Co deposited at $200{ }^{\circ} \mathrm{C}$, in which the 4 marked dots belong to Si (220) reference. 

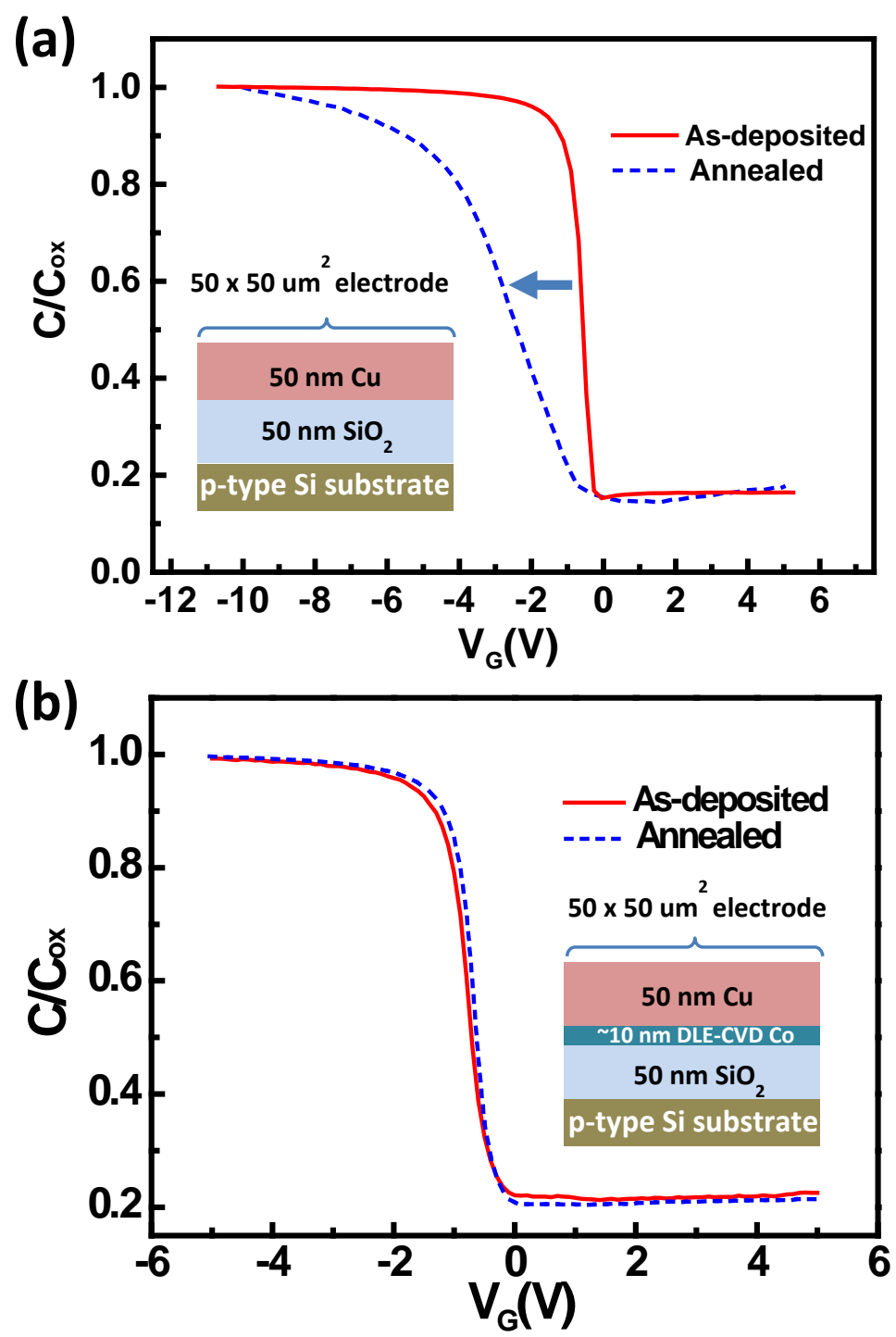

Figure 5. C-V measurements on microcapacitor structures for the evaluation of Cu blocking capability. (a) $\mathrm{Cu} / \mathrm{SiO}_{2} / \mathrm{Si}$ system, showing $\sim 2 \mathrm{~V}$ shift to the negative side; (b) $\mathrm{Cu} / \mathrm{Co} / \mathrm{SiO}_{2} / \mathrm{Si}$ system, showing no observable shift of C-V curve. All measurements started at positive $5 \mathrm{~V}$ and scanned from positive bias toward negative bias. 

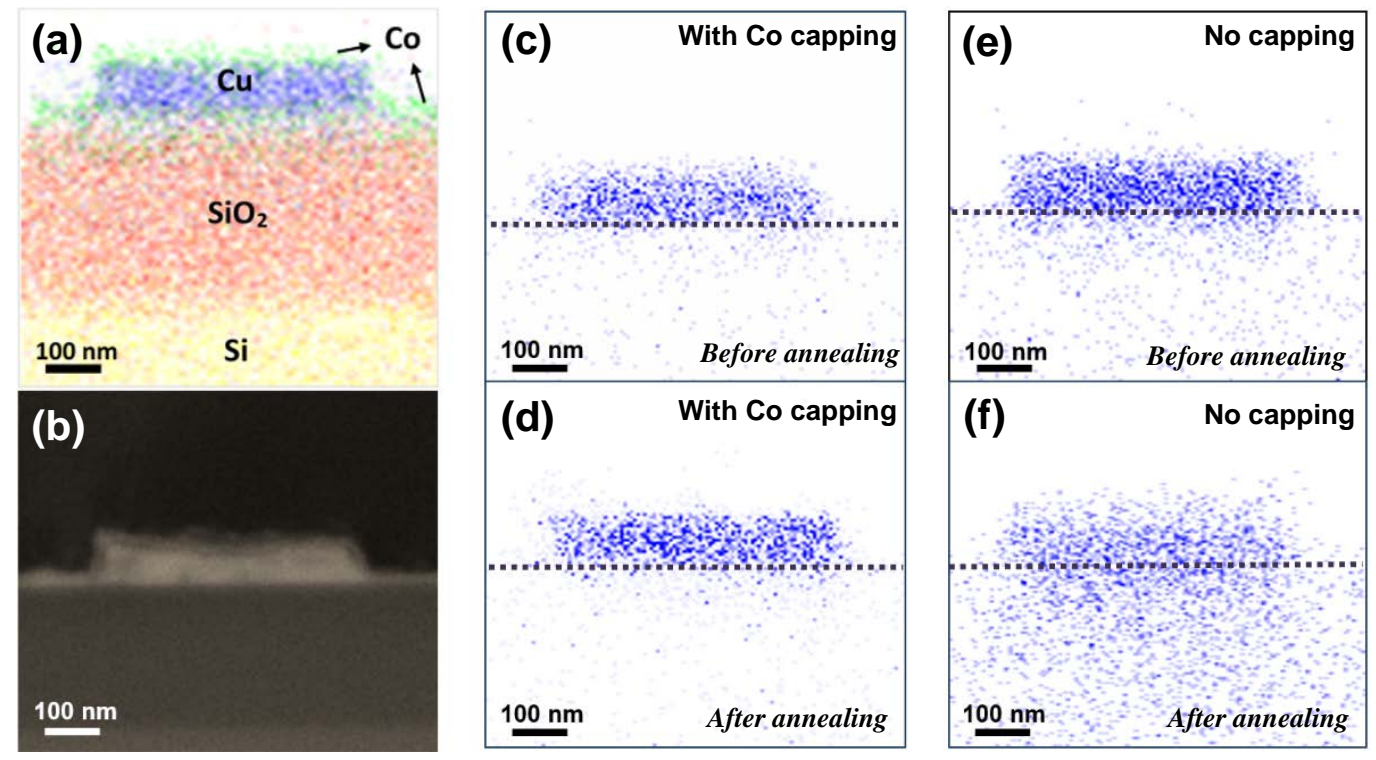

Figure 6. Demonstration of the application of DLE-CVD Co as an all-around encapsulation layer for $\mathrm{Cu}$ interconnects at nanoscales. (a) Cross-section EDAX elemental mapping of a Coencapsulated Cu wire; (b) Cross-section SEM image of a Co-encapsulated Cu wire; (c-d) Crosssection $\mathrm{Cu} \mathrm{Ka12D}$ mapping of the $\mathrm{Cu}$ wires with Co encapsulation before and after annealing at $600{ }^{\circ} \mathrm{C}$ for 2 hours, showing no obvious diffusion of $\mathrm{Cu}$; (e-f) Cross-section $\mathrm{Cu} \mathrm{Ka} 1$ 2D mapping of the $\mathrm{Cu}$ wires without any capping layer before and after annealing at $600{ }^{\circ} \mathrm{C}$ for 2 hours, showing substantial amount of $\mathrm{Cu}$ diffusion into $\mathrm{SiO}_{2}$. 


\section{Supporting Information.}

The supporting information is available free of charge on the ACS Publication website, including description of DLE-CVD system and Co precursor, fabrication process of test structures, step coverage evaluation method in a horizontal trench test structure, illustration of electrical test structures, as well as additional TEM and ED results.

\section{Corresponding Author}

* gordon@chemistry.harvard.edu

\section{Author Contributions}

The manuscript was written through contributions of all authors. All authors have given approval to the final version of the manuscript.

\section{ACKNOWLEDGMENT}

The work was supported in part by the Center for the Next Generation of Materials by Design, an Energy Frontier Research Center funded by the U.S. Department of Energy, Office of Science and in part by the U.S. Air Force Office of Scientific Research under a subcontract from the Charles Stark Draper Laboratory. Some of the work was performed at Harvard University's Center for Nanoscale Systems (CNS), a member of the National Nanotechnology Infra-structure Network (NNIN), and at Harvard University’s X-ray laboratory. We thank Dr. Andrew Magyar for help with APT sample preparation, measurements, data analysis and discussions. 


\section{REFERENCES}

1. Allara, D. L., A Perspective on Surfaces and Interfaces. Nature 2005, 437 (7059), 638639.

2. Hu, J.; Yu, M. F., Meniscus-Confined Three-Dimensional Electrodeposition for Direct Writing of Wire Bonds. Science 2010, 329 (5989), 313-316.

3. $\quad$ Ramm, P.; Klumpp, A.; Weber, J.; Lietaer, N.; Taklo, M.; Raedt, W. D.; Fritzsch, T.; Couderc, P. In 3D Integration Technology: Status and Application Development, IEEE Eur. Solid-State Circuits Conf. (ESSCIRC 2010), 14-16 Sept. 2010; 2010; 9-16.

4. Baklanov, M. R.; Adelmann, C.; Zhao, L.; De Gendt, S., Advanced Interconnects: Materials, Processing, and Reliability. ECS J. Solid State Sci. Technol. 2015, 4 (1), Y1-Y4.

5. Xu, W. H.; Wang, L.; Guo, Z.; Chen, X.; Liu, J.; Huang, X. J., Copper Nanowires as Nanoscale Interconnects: Their Stability, Electrical Transport, and Mechanical Properties. ACS Nano 2015, 9 (1), 241-250.

6. Hau-Riege, C. S., An introduction to Cu electromigration. Microelectron. Reliab. 2004, 44 (2), 195-205.

7. Hideharu, S.; Kaoru, S.; Takeshi, M.; Yukihiro, S., Atomic Layer Deposited Co(W) Film as a Single-Layered Barrier/Liner for Next-Generation Cu-Interconnects. Jpn. J. Appl. Phys. 2012, 51 (5S), 05EB02.

8. $\quad$ Kang, C. S.; Cho, H. J.; Kim, Y. H.; Choi, R.; Onishi, K.; Shahriar, A.; Lee, J. C., Characterization of Resistivity and Work Function of Sputtered-TaN Film for Gate Electrode Applications. J. Vac. Sci. Technol., B: Nanotechnol. Microelectron.: Mater., Process., Meas., Phenom. 2003, 21 (5), 2026-2028. 
9. Kwak, M. Y.; Shin, D. H.; Kang, T. W.; Kim, K. N., Characteristics of WN Diffusion Barrier Layer for Copper Metallization. Phys. Status Solidi A 1999, 174 (1), R5-R6.

10. Gambino, J. P. In Copper Interconnect Technology for the $22 \mathrm{~nm}$ Node, Int. Symp. VLSI Technology, Systems, and Applications, Proc. (VLSI-TSA 2011), 25-27 April 2011; 2011; 1-2.

11. Zhang, W.; Brongersma, S. H.; Richard, O.; Brijs, B.; Palmans, R.; Froyen, L.; Maex, K., Influence of the Electron Mean Free Path on the Resistivity of Thin Metal Films. Microelectron. Eng. 2004, 76 (1-4), 146-152.

12. Wu, W.; Brongersma, S. H.; Van Hove, M.; Maex, K., Influence of Surface and GrainBoundary Scattering on the Resistivity of Copper in Reduced Dimensions. Appl. Phys. Lett. 2004, 84 (15), 2838-2840.

13. Sun, T.; Yao, B.; Warren, A. P.; Barmak, K.; Toney, M. F.; Peale, R. E.; Coffey, K. R., Surface and Grain-Boundary Scattering in Nanometric Cu Films. Phys. Rev. B 2010, 81 (15), 155454.

14. Huang, C. L.; Lai, C. H.; Tsai, P. H.; Huang, H. A.; Lin, J. C.; Lee, C., Characteristics of Reactively Sputtered Niobium Nitride Thin Films as Diffusion Barriers for Cu Metallization. Electron. Mater. Lett. 2013, 9 (5), 593-597.

15. Kohn, A.; Eizenberg, M.; Shacham-Diamand, Y., Copper Grain Boundary Diffusion in Electroless Deposited Cobalt Based Films and its Influence on Diffusion Barrier Integrity for Copper Metallization. J. Appl. Phys. 2003, 94 (5), 3015-3024.

16. Elko-Hansen, T. D. M.; Dolocan, A.; Ekerdt, J. G., Atomic Interdiffusion and Diffusive Stabilization of Cobalt by Copper During Atomic Layer Deposition from Bis(N-tert-butyl-N'ethylpropionamidinato) Cobalt(II). J. Phys. Chem. Lett. 2014, 5 (7), 1091-1095. 
17. Borrajo, J.; Heras, J. M., Electrical Conductivity of Thin Cobalt Films. Surf. Sci. 1971, 28

(1), 132-144.

18. Yang, C. C.; Flaitz, P.; Wang, P. C.; Chen, F.; Edelstein, D., Characterization of Selectively Deposited Cobalt Capping Layers: Selectivity and Electromigration Resistance. IEEE Electron. Device Lett. 2010, 31 (7), 728-730.

19. Zhang, H.; Poole, J.; Eller, R.; Keefe, M., Cobalt Sputtering Target and Sputter Deposition of Co Thin Films for Cobalt Silicide Metallization. J. Vac. Sci. Technol. A 1999, 17 (4), 1904-1910.

20. Ko, Y. K.; Park, D. S.; Seo, B. S.; Yang, H. J.; Shin, H. J.; Kim, J. Y.; Lee, J. H.; Lee, W. H.; Reucroft, P. J.; Lee, J. G., Studies of Cobalt Thin Films Deposited by Sputtering and MOCVD. Mater. Chem. Phys. 2003, 80 (2), 560-564.

21. Papadopoulos, N.; Karayianni, C. S.; Tsakiridis, P.; Sarantopoulou, E.; Hristoforou, E., Effects of MOCVD Thin Cobalt Films' Structure and Surface Characteristics on their Magnetic Behavior. Chem. Vap. Deposition 2011, 17 (7-9), 211-220.

22. Li, Z.; Gordon, R. G.; Pallem, V.; Li, H.; Shenai, D. V., Direct-Liquid-Injection Chemical Vapor Deposition of Nickel Nitride Films and Their Reduction to Nickel Films. Chem. Mater. 2010, 22 (10), 3060-3066.

23. Yang, J.; Li, K.; Feng, J.; Gordon, R. G., Direct-Liquid-Evaporation Chemical Vapor Deposition of Smooth, Highly Conformal Cobalt and Cobalt Nitride Thin Films. J. Mater. Chem. C 2015, 3 (46), 12098-12106.

24. Song, M. K.; Kang, S. W.; Rhee, S. W., Direct Liquid Injection Metal-Organic Chemical Vapor Deposition of $\mathrm{HfO}_{2}$ Thin Films Using $\mathrm{Hf}($ dimethylaminoethoxide) 4 . Thin Solid Films 2004, 450 (2), 272-275. 
25. Wang, X.; Gordon, R. G., Smooth, Low-Resistance, Pinhole-Free, Conformal Ruthenium Films by Pulsed Chemical Vapor Deposition. ECS J. Solid State Sci. Technol. 2013, 2 (3), 41-44.

26. Lim, B. S.; Rahtu, A.; Park, J. S.; Gordon, R. G., Synthesis and Characterization of Volatile, Thermally Stable, Reactive Transition Metal Amidinates. Inorg. Chem. 2003, 42 (24), 7951-7958.

27. Knop, M.; Mulvey, P.; Ismail, F.; Radecka, A.; Rahman, K. M.; Lindley, T. C.; Shollock, B. A.; Hardy, M. C.; Moody, M. P.; Martin, T. L.; Bagot, P. A. J.; Dye, D., A New Polycrystalline Co-Ni Superalloy. JOM 2014, 66 (12), 2495-2501.

28. Premkumar, P. A.; Bahlawane, N.; Reiss, G.; Kohse-Höinghaus, K., CVD of Metals Using Alcohols and Metal Acetylacetonates, Part II: Role of Solvent and Characterization of Metal Films Made by Pulsed Spray Evaporation CVD. Chem. Vap. Deposition 2007, 13 (5), 227231.

29. Lane, P. A.; E.Oliver, P.; Wright, P. J.; Reeves, C. L.; Pitt, A. D.; Cockayne, B., Metal Organic CVD of Cobalt Thin Films Using Cobalt Tricarbonyl Nitrosyl. Chem. Vap. Deposition 1998, 4 (5), 183-186.

30. Bhandari, H. B.; Yang, J.; Kim, H.; Lin, Y.; Gordon, R. G.; Wang, Q. M.; Lehn, J. S. M.; Li, H.; Shenai, D., Chemical Vapor Deposition of Cobalt Nitride and its Application as an Adhesion-Enhancing Layer for Advanced Copper Interconnects. ECS J. Solid State Sci. Technol. 2012, 1 (5), N79-N84.

31. Au, Y.; Wang, Q. M.; Li, H.; Lehn, J. S. M.; Shenai, D. V.; Gordon, R. G., Vapor Deposition of Highly Conformal Copper Seed Layers for Plating Through-Silicon Vias (TSVs). J. Electrochem. Soc. 2012, 159 (6), D382-D385. 
32. Hono, K.; Raabe, D.; Ringer, S. P.; Seidman, D. N., Atom Probe Tomography of Metallic Nanostructures. MRS Bull. 2016, 41 (01), 23-29.

33. Gault, B.; Moody, M. P.; Cairney, J. M.; Ringer, S. P., Atom Probe Crystallography. Mater. Today 2012, 15 (9), 378-386.

34. Araullo-Peters, V. J.; Gault, B.; Shrestha, S. L.; Yao, L.; Moody, M. P.; Ringer, S. P.; Cairney, J. M., Atom Probe Crystallography: Atomic-Scale 3-D Orientation Mapping. Scr. Mater. 2012, 66 (11), 907-910.

35. Hausmann, D. M.; Gordon, R. G., Surface Morphology and Crystallinity Control in the Atomic Layer Deposition (ALD) of Hafnium and Zirconium Oxide Thin Films. J. Cryst. Growth 2003, 249 (1-2), 251-261.

36. Dubey, R.; Gupta, A.; Pivin, J. C., Amorphization in Iron Nitride Thin Films Prepared by Reactive Ion-Beam Sputtering. Phys. Rev. B 2006, 74 (21), 214110.

37. Nishizawa, T.; Ishida, K., The $\mathrm{Co}-\mathrm{Cu}$ (Cobalt-Copper) System. Bull. Alloy Phase Diagrams 1984, 5 (2), 161-165.

38. Klesko, J. P.; Kerrigan, M. M.; Winter, C. H., Low Temperature Thermal Atomic Layer Deposition of Cobalt Metal Films. Chem. Mater. 2016, 28 (3), 700-703.

39. Au, Y.; Lin, Y.; Gordon, R. G., Filling Narrow Trenches by Iodine-Catalyzed CVD of Copper and Manganese on Manganese Nitride Barrier/Adhesion Layers. J. Electrochem. Soc. 2011, 158 (5), D248-D253.

40. Li, Z.; Gordon, R. G.; Farmer, D. B.; Lin, Y.; Vlassak, J., Nucleation and Adhesion of ALD Copper on Cobalt Adhesion Layers and Tungsten Nitride Diffusion Barriers. Electrochem. Solid State Lett. 2005, 8 (7), G182-G185. 
41. Zhang, L.; Zhou, J. P.; Im, J.; Ho, P. S.; Aubel, O.; Hennesthal, C.; Zschech, E. In Effects of Cap Layer and Grain Structure on Electromigration Reliability of Cu/Low-k Interconnects for 45 nm Technology Node, IEEE Reliab. Phys. Symp. (IRPS 2010), 2-6 May 2010; 2010; 581-585. 
Table of Contents
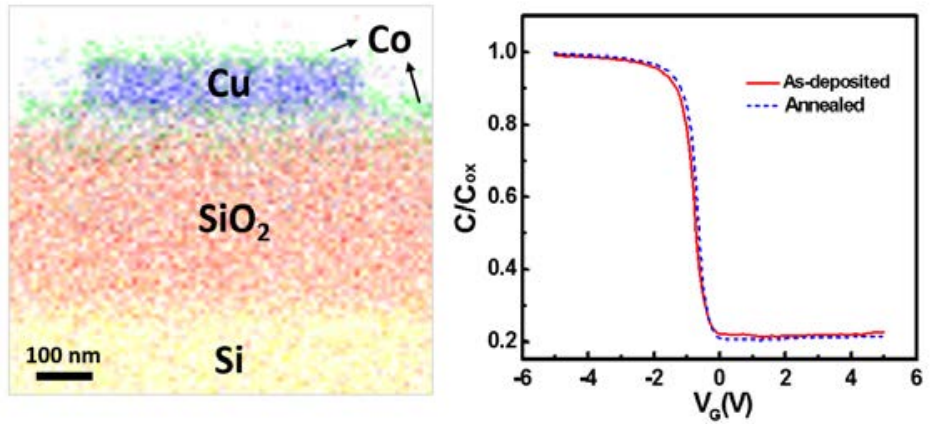


\section{Supporting Information}

Direct-liquid-evaporation Chemical Vapor Deposition of Nanocrystalline Cobalt Metal for Nanoscale Copper Interconnect Encapsulation

Jun Feng ${ }^{\dagger}$, Xian Gong ${ }^{\ddagger}$, Xiabing Lou ${ }^{\dagger}$, and Roy G. Gordon ${ }^{*},+\neq$

† Department of Chemistry and Chemical Biology, Harvard University, Cambridge, MA 02138, USA

‡ John A. Paulson School of Engineering and Applied Sciences, Harvard University, Cambridge, MA 02138, USA

* gordon@chemistry.harvard.edu

\section{Table of contents}

Figure S1. Co precursor for DLE-CVD Co Deposition

Figure S2. DLE-CVD Co System Diagram

Figure S3. Schematic flow chart of the fabrication process of horizontal trench test structures

Figure S4. Schematic illustration of the assessment of step coverage on trench test structure

Figure S5. Additional high-resolution TEM images

Figure S6. Electron diffraction (ED) patterns

Table S1-S3. ED data analysis for phase identification

Table S4. Resistivity of DLE-CVD Co with different carbon contents 


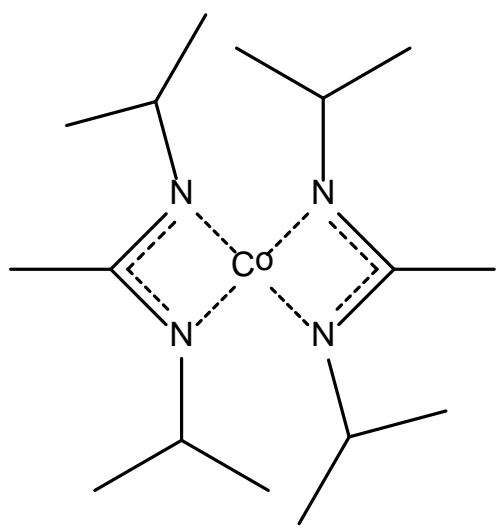

Name: bis(N,N'-diisopropylacetamidinato)cobalt(II)

Melting Point: $84^{\circ} \mathrm{C}$ (solid at room temp.)

Bubbler Temperature: room temperature

Precursor Solution Vaporization Temperature: $150 \sim 180^{\circ} \mathrm{C}$

Vapor Pressure: $30 \mathrm{mTorr}$ at $40^{\circ} \mathrm{C}$

Figure S1. Co precursor for DLE-CVD Co Deposition.

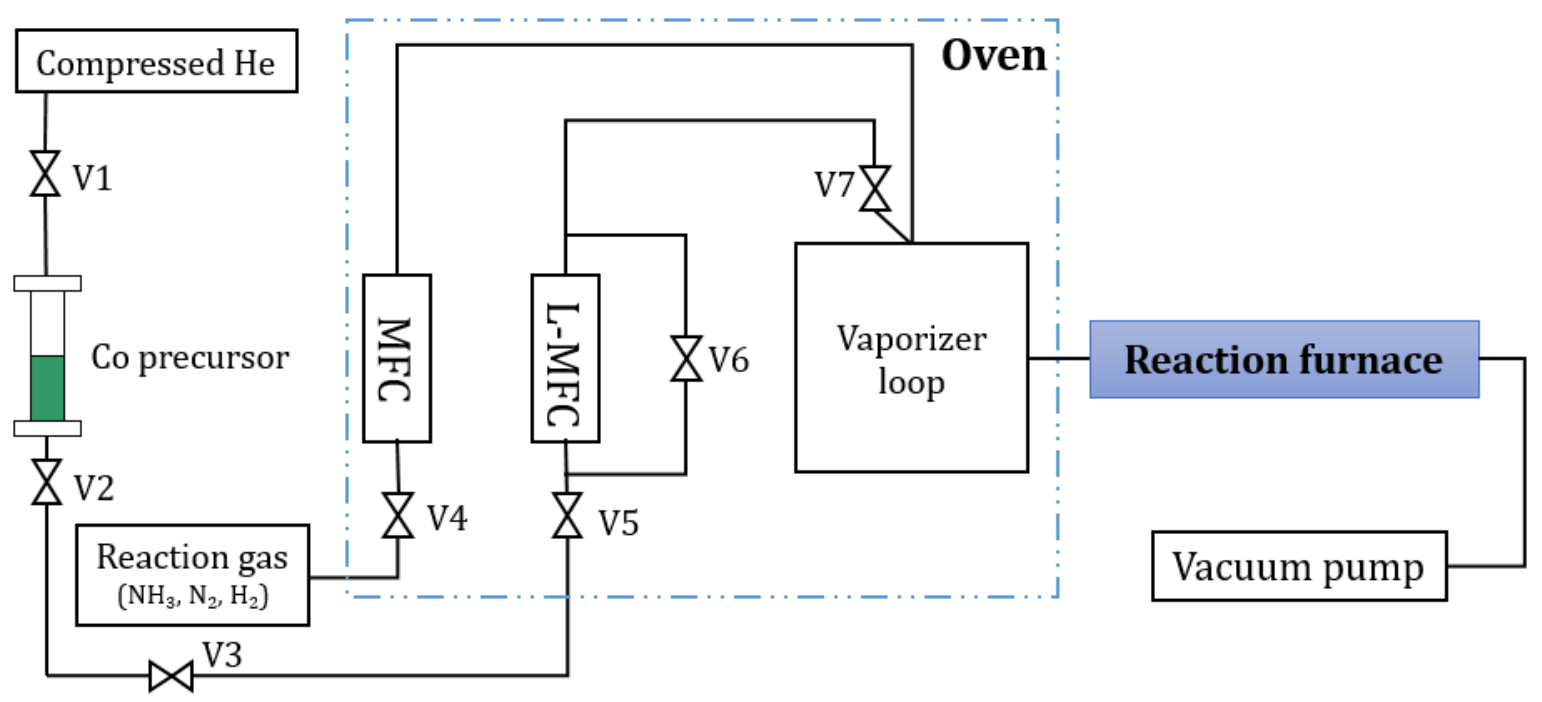

Figure S2. DLE-CVD Co System Diagram. 


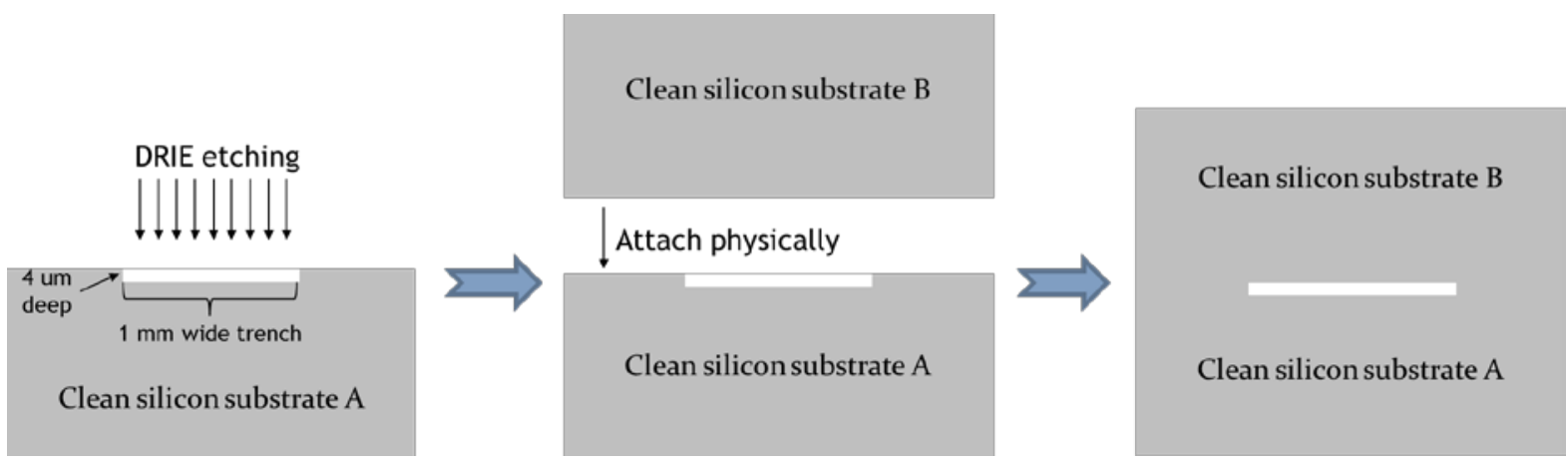

Figure S3. Schematic flow chart (cross-section view) of the fabrication process of horizontal trench test structures on which step coverage evaluation of DLE-CVD Co is conducted. In brief, an atomically flat silicon chip was first coated with $2 \mu \mathrm{m}$ of positive photoresist as a soft mask, and patterned with $500 \mu \mathrm{m}$ wide $0.5 \mathrm{~cm}$ long exposed lines by photolithography. A $500 \mu \mathrm{m}$ wide, $2 \mu \mathrm{m}$ deep shallow trench was created by a Bosch-type deep silicon reactive ion etching (DRIE) process with $\mathrm{SF}_{6}$ and $\mathrm{C}_{4} \mathrm{~F}_{6}$ gases, and thoroughly cleaned afterwards. Finally, the chip was physically capped with another atomically flat silicon chip to cover part of the $0.5 \mathrm{~cm}$ length, leaving one end exposed as the opening of the parallel deep trench.

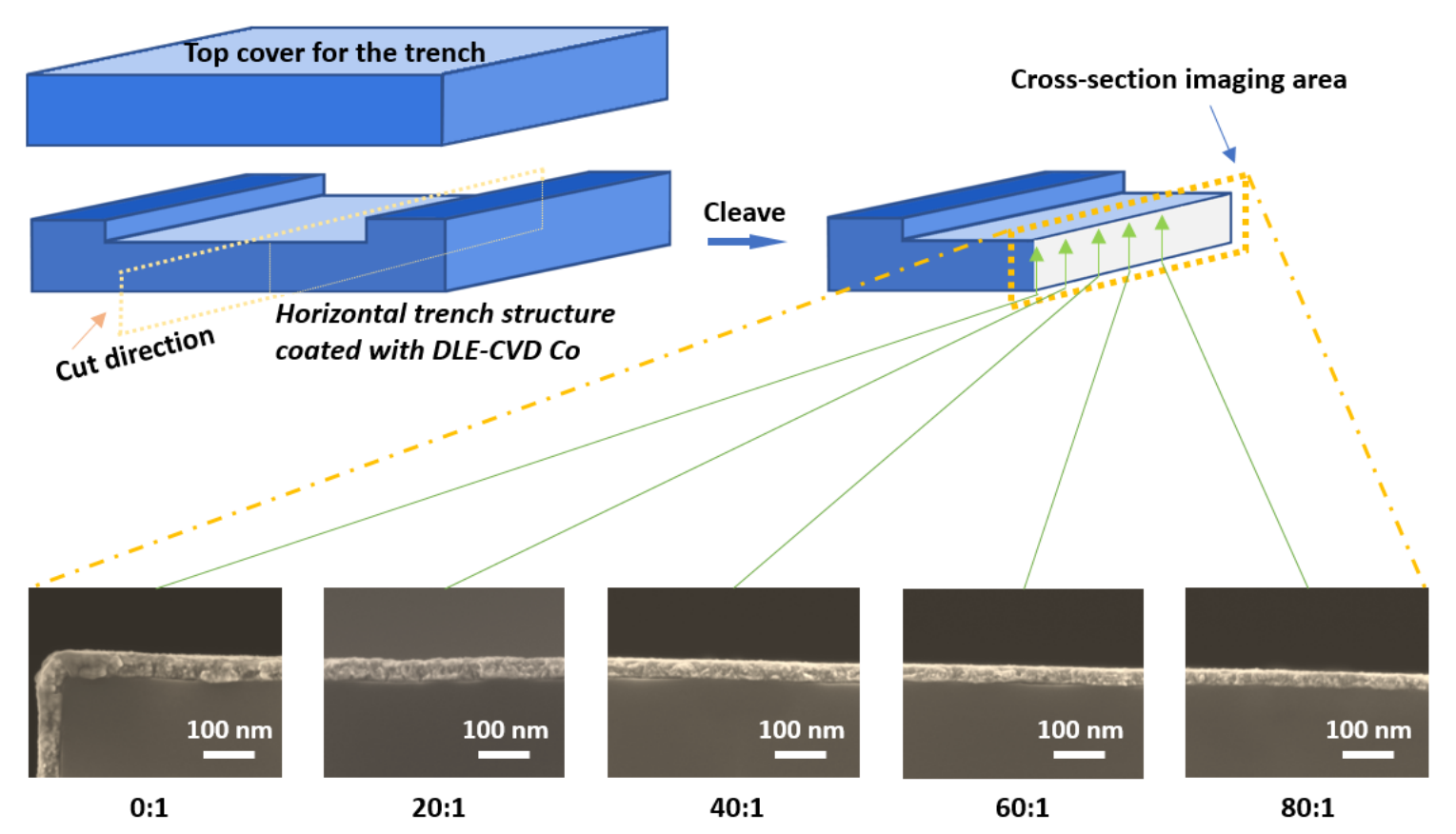

Figure S4. Schematic illustration of the assessment of step coverage on the horizontal trench test structure described in Figure S3. The test structure was coated with DLE-CVD Co, then cleave along the direction of the horizontal trench. Then cross-section SEM imaging at different depth with different aspect ratios were conducted and measured thickness of Co layer. The DLE-CVD Co sample shown in the images was deposited at $200{ }^{\circ} \mathrm{C}$. 

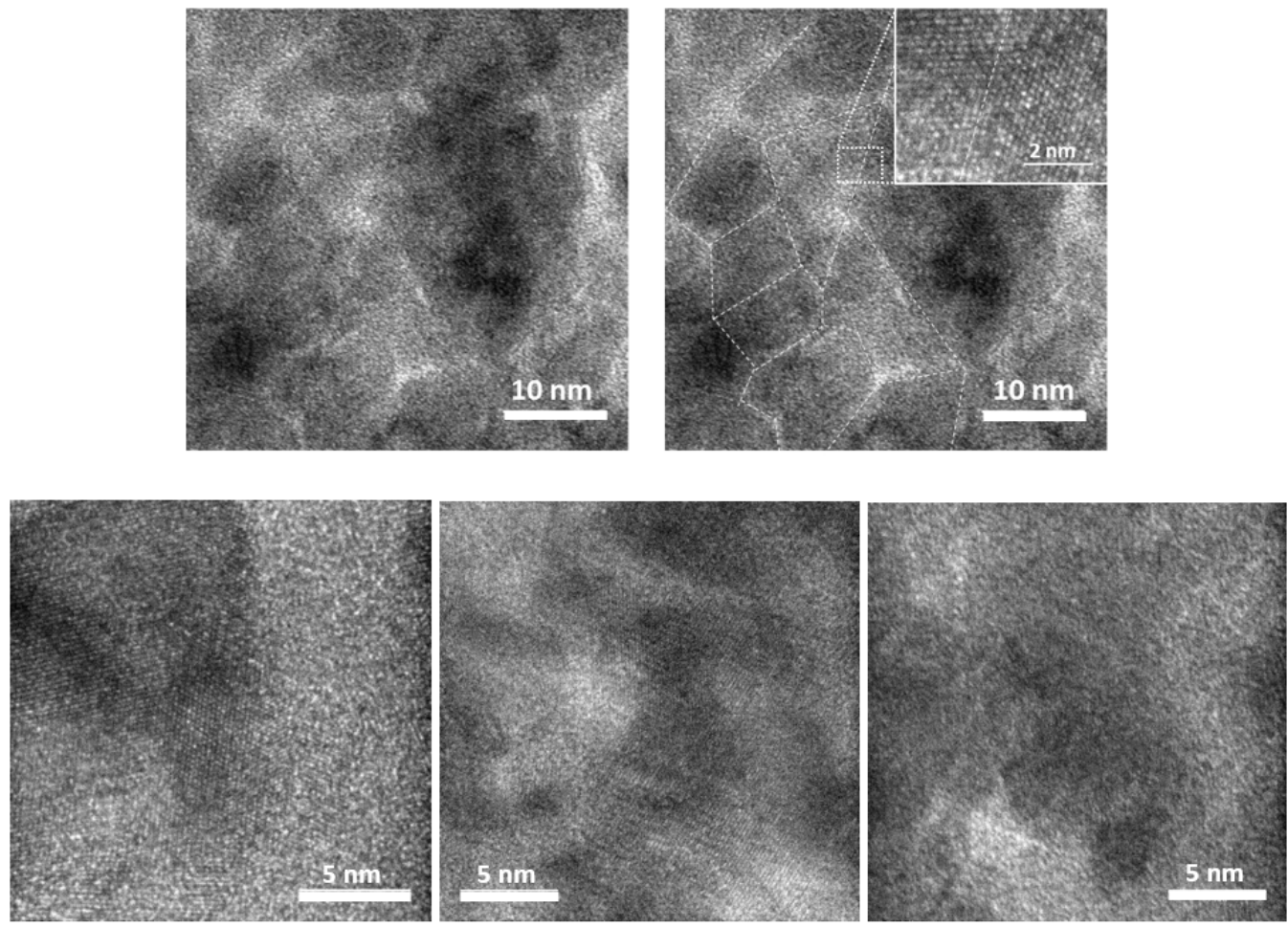

Figure S5. High-resolution TEM images of DLE-CVD Co deposited in $200{ }^{\circ} \mathrm{C}$. Top two images show crystal domains without and with dashed lines as indicators of domain boundaries; Bottom three images are additioanl high resolution TEM images in nearby areas.
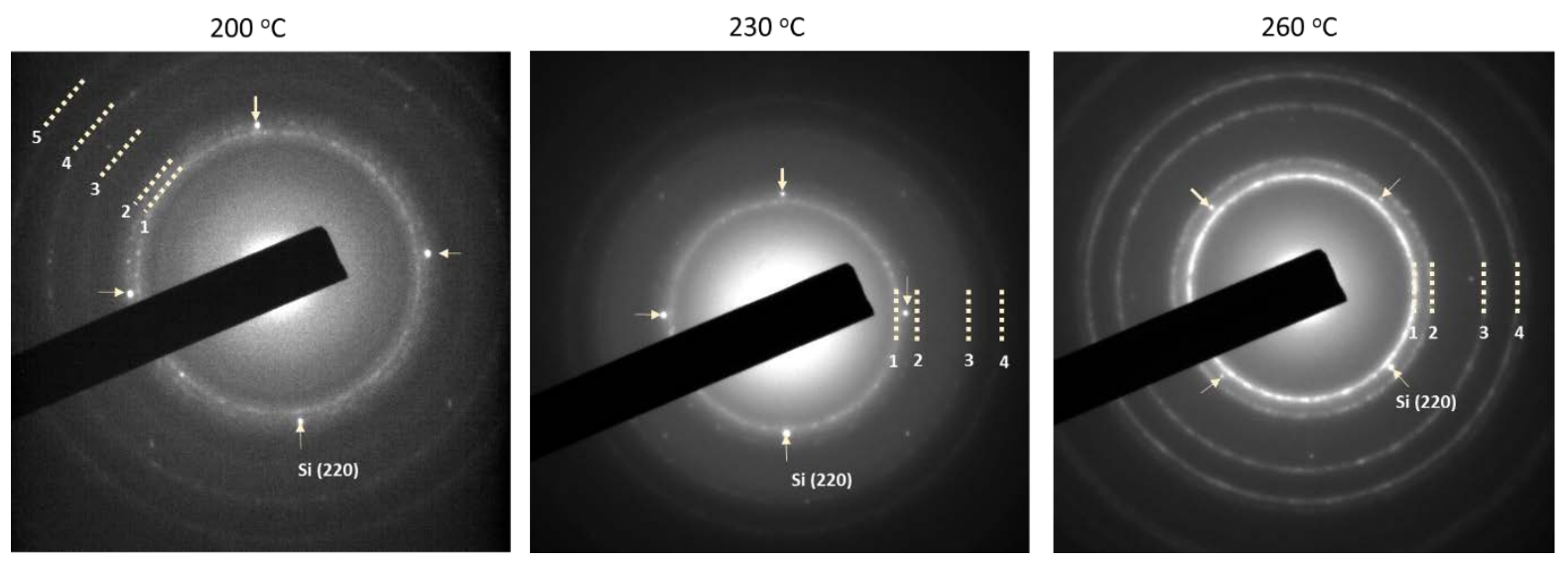

Figure S6. Electron Diffraction patterns for DLE-CVD Co samples deposited at different temperatures. 
Table S1. Theoretical and experimental ED results for a DLE-CVD Co film deposited on a TEM grid formed by a $\mathrm{SiN}_{\mathrm{x}}$ membrane (50 nm thick) suspended across a hole in a silicon substrate. The film was deposited using a mixture of $100 \mathrm{sccm} \mathrm{NH}$ and $100 \mathrm{sccm} \mathrm{H}_{2}$ gases as co-reactants. The deposition temperature is set to be $200{ }^{\circ} \mathrm{C}$. The rings can be assigned to the cubic Co phase and hexaganol Co phase, and the discrete spots came from the Si substrate, which was used for internal calibration.

\begin{tabular}{|c|c|c|c|c|c|c|c|}
\hline \multirow[b]{3}{*}{ No. } & \multicolumn{4}{|c|}{ Theoretical value } & \multirow{2}{*}{\multicolumn{3}{|c|}{$\begin{array}{l}\text { Experimental value } \\
\text { Temperature }=200^{\circ} \mathrm{C}\end{array}$}} \\
\hline & \multicolumn{2}{|c|}{ FCC $\beta$-Co } & \multicolumn{2}{|c|}{$\mathrm{Hcp} \alpha-$ Сo } & & & \\
\hline & hkl & $d(A)$ & hkl & $d(A)$ & Ring no. & Calculated d (A) & error \\
\hline 1 & 111 & 2.05 & 002 & 2.03 & 1 & 2.0679 & $0.87 \%$ \\
\hline 2 & & & 101 & 1.92 & 2 & 1.9071 & $-0.67 \%$ \\
\hline 3 & & & 102 & 1.48 & 3 & 1.5307 & $3.43 \%$ \\
\hline 4 & 220 & 1.25 & & & 4 & 1.2636 & $1.09 \%$ \\
\hline 5 & 311 & 1.07 & & & 5 & 1.0998 & $2.79 \%$ \\
\hline
\end{tabular}

For Table S1,the indices of planes (hkl) and interplanar spacings (d) represent the reference crystal structures of fcc $\beta$-Co (JCPDS Card No.15-0806), hcp $\alpha$-Co (JCPDS Card No. 71-4239).

Table S2. Theoretical and experimental ED Results for a DLE-CVD Co film made using a mixture of $100 \mathrm{sccm} \mathrm{NH}$ and $100 \mathrm{sccm} \mathrm{H}_{2}$ as coreactants deposited at $230{ }^{\circ} \mathrm{C}$. The rings belong to the cubic Co phase and the discrete spots came from the Si substrate, which was used for internal calibration.

\begin{tabular}{|c|c|c|c|c|c|}
\hline & \multicolumn{2}{|c|}{ Theoretical value } & \multicolumn{3}{|c|}{ Experimentalvalue } \\
\hline & \multicolumn{2}{|c|}{ FCC $\beta$-Co } & \multicolumn{3}{|c|}{ Temperature $=230^{\circ} \mathrm{C}$} \\
\hline No. & hkl & $d(A)$ & Ring no. & Calculated d (A) & error \\
\hline 1 & 111 & 2.05 & 1 & 2.0523 & $0.11 \%$ \\
\hline 2 & 200 & 1.77 & 2 & 1.7884 & $1.04 \%$ \\
\hline 3 & 220 & 1.25 & 3 & 1.255 & $0.40 \%$ \\
\hline 4 & 311 & 1.07 & 4 & 1.0676 & $-0.22 \%$ \\
\hline
\end{tabular}

For Table S2,the indices of planes (hkl) and interplanar spacings (d) represent the reference crystal structures of fcc $\beta$-Co (JCPDS Card No.15-0806) 
Table S3. Theoretical and experimental ED Results for a DLE-CVD Co film made using a mixture of $100 \mathrm{sccm} \mathrm{NH}$ and $100 \mathrm{sccm} \mathrm{H}$ as coreactants deposited at $260{ }^{\circ} \mathrm{C}$. The rings belong to the cubic Co phase and the discrete spots came from the Si substrate, which was used for internal calibration.

\begin{tabular}{|c|c|c|c|c|c|}
\hline & \multicolumn{2}{|c|}{ Theoretical value } & \multicolumn{3}{|c|}{ Experimental value } \\
\hline & \multicolumn{2}{|c|}{ FCC $\beta-C o$} & \multicolumn{3}{|c|}{ Temperature $=260^{\circ} \mathrm{C}$} \\
\hline No. & hkl & $d(A)$ & Ring no. & Calculated d (A) & error \\
\hline 1 & 111 & 2.05 & 1 & 2.0523 & $0.11 \%$ \\
\hline 2 & 200 & 1.77 & 2 & 1.8355 & $3.7 \%$ \\
\hline 3 & 220 & 1.25 & 3 & 1.259 & $0.72 \%$ \\
\hline 4 & 311 & 1.07 & 4 & 1.0863 & $1.52 \%$ \\
\hline
\end{tabular}

For Table S3,the indices of planes (hkl) and interplanar spacings (d) represent the reference crystal structures of fcc $\beta$-Co (JCPDS Card No.15-0806)

From Table S1 to S3, the error in the Experimental value column is calculated as the difference between the measured value and the closest reference value, presented as a percentage.

Table S4. Resistivity of DLE-CVD Co with different carbon contents

\begin{tabular}{|c||c|c|c|c|}
\hline Deposition Temperature $\left({ }^{\circ} \mathrm{C}\right)$ & 200 & 230 & 260 & 290 \\
\hline Carbon Content $(\mathrm{at} \%)$ & $<1$ & $<2$ & 5 & 15 \\
\hline Resistivity $(\mu \mathrm{Ohm} \cdot \mathrm{cm})$ & 25 & 30 & 100 & 195 \\
\hline
\end{tabular}

